\title{
Hydrogenation of Anthracene Catalyzed by Surfactant-Protected Gold Nanoparticles in Aqueous Solution: Size Dependence
}

\author{
Jin-Pei Deng, Wen-Chen Shih, and Chung- \\ Yuan Mou*[a]
}

Size-sensitive catalysis of chemical reactions by metallic nanoparticles (NPs) is an important research direction attracting a lot of attention. ${ }^{[1]}$ In most of the investigations, the NPs are supported on a surface, usually a metal oxide, to allow formation of highly dispersed NPs. ${ }^{[2]}$ For heterogeneous catalysts involving gold NPs deposited on metal oxides, size-sensitive catalysis by gold NPs is reported for the $\mathrm{CO}$ oxidation, ${ }^{[3 a]}$ the propylene epoxidation $^{[3 \mathrm{~b}]}$ and the selective hydrogenation. ${ }^{[4-10]}$ However, there often exists a strong interaction between the NP and the support which makes the size effect in catalysis difficult to understand. In a second approach colloidal particles in solution are used for catalysis in the liquid state. ${ }^{[11]}$ Compared to supported catalysts, the size and the shape of colloidal particles can easily be controlled. Also the strong interaction with the support is essentially eliminated. In contrast to supported gold catalysis, a clear size-sensitive catalysis effect has not been reported in liquid-phase catalysis by gold colloids. Herein, we report the hydrogenation of anthracene catalyzed by size-controlled gold colloids which are protected by ionic surfactants in aqueous solution at room temperature. The sizes of gold NPs in solution may be controlled by the properties of the surfactant and its concentration used for the preparation (cationic surfactant: hexadecyltrimethylammonium bromide, $C T A B$, and anionic surfactant: sodium dodecyl sulfate, SDS). Then, the less volatile reactant such as anthracene was solubilized in surfactant-protected gold colloids to study its hydrogenation catalyzed by gold NPs. A remarkable size-dependent catalytic activity is found. Compared with the reported hydrogenation of anthracene catalyzed by $\mathrm{TiCl}_{4}{ }^{[12]}$ our $\mathrm{Au}$ colloidal particles exhibit higher catalytic activity and higher selectivity at lower reaction temperatures.

For the preparation of gold NPs in the SDS system, $0.02 \mathrm{~mL}$ of an aqueous $25 \mathrm{~mm} \mathrm{HAuCl} \cdot 3 \mathrm{H}_{2} \mathrm{O}$ solution was added to $5 \mathrm{~mL}$ of an aqueous solution of $20 \mathrm{~mm}$ SDS. Then, $0.06 \mathrm{~mL}$ of an aqueous $\mathrm{NaBH}_{4}(11 \mathrm{~mm}$ ) solution was added (see left side of Scheme 1). After the addition of $\mathrm{NaBH}_{4}$, the solution turned pink and an UV/Vis absorption spectrum, shown in Figure $1 \mathrm{a}$ (solid line), was measured. The surface plasmon resonance (SPR) band at $520 \mathrm{~nm}$ indicates the formation of gold NPs. ${ }^{[13]}$ The average diameter of gold NPs (denoted as Au@SDS) is

[a] Dr. J.-P. Deng, W.-C. Shih, Prof. C.-Y. Mou

Department of Chemistry

National Taiwan University, Taipei, Taiwan 106 (Taiwan)

Fax: $(+886)$ 2-2366-0954

E-mail:cymou@ntu.edu.tw 
SDS (or CTAB) solution
1. $\mathrm{HAuCl}_{4}$

2. $\mathrm{NaBH}_{4}$

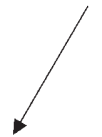

Au NP-containing SDS (or CTAB) solution

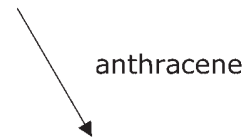

anthracene-containing SDS (or CTAB) solution

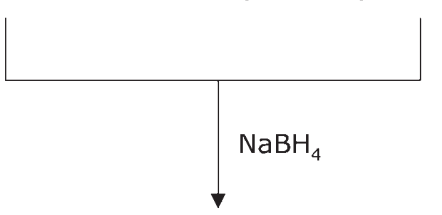

anthracene hydrogenation reaction

Scheme 1. Flow chart of the preparation and reaction steps.

a)

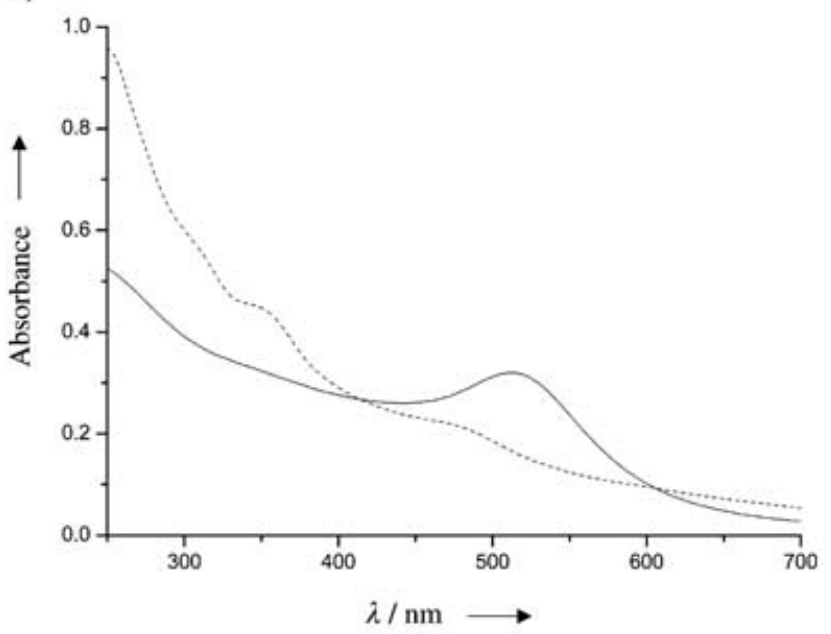

b)

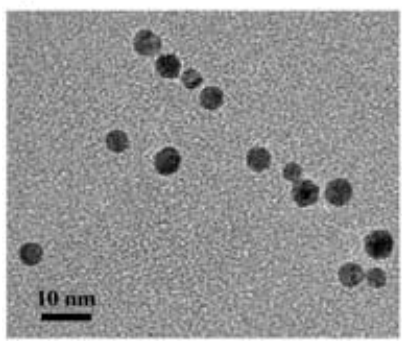

c)

Figure 1. a) UV/Vis spectra of gold particles prepared by reduction of $20 \mu \mathrm{L}$ $\mathrm{HAuCl}_{4}$ in $5 \mathrm{~mL}$ aqueous solution of SDS (20 m M) with $60 \mu \mathrm{L} \mathrm{NaBH}_{4}(-)$ and $9 \mathrm{~mL} \mathrm{HAuCl}_{4}$ in $300 \mathrm{~mL}$ aqueous solution of CTAB (0.1 M) with $27 \mathrm{~mL}$ $\mathrm{NaBH}_{4}(----)$. Conditions: $\left[\mathrm{HAuCl}_{4}\right]=25 \mathrm{~mm}$ and $\left[\mathrm{NaBH}_{4}\right]=11 \mathrm{~mm}$. b) TEM image of gold particles prepared in the reaction solution of SDS $(-)$ in (a). c) TEM image of gold particles prepared in the reaction solution of CTAB $(---)$ in (a).

$5.4 \mathrm{~nm}$, as measured by transmission electron microscopy (TEM; Figure $1 \mathrm{~b}$ ). We then used the same procedure but the SDS surfactant was replaced by the CTAB system (denoted as Au@CTAB). The absorption spectrum of gold NPs produced in an aqueous $0.1 \mathrm{M}$ CTAB solution is shown in Figure $1 \mathrm{a}$ (dash line). The SPR absorption band is much broader, indicating a smaller particle size. The TEM micrograph in Figure $1 \mathrm{c}$ shows that the average diameter of Au@CTAB NP is $2.7 \mathrm{~nm}$.

First, anthracene was dissolved in an aqueous SDS solution. The solubilized concentration of anthracene was $15.3 \mu \mathrm{m}$. Then, $\mathrm{HAuCl}_{4}$ and $\mathrm{NaBH}_{4}$ were successively added. The solution displays the characteristic UV/Vis SPR absorption near $520 \mathrm{~nm}$ (Figure 2a) which is expected for gold colloids (confirmed by TEM images; the images are not shown here). Interestingly, the characteristic absorption peak of anthracene at $253 \mathrm{~nm}$ drastically decreased. If only $\mathrm{NaBH}_{4}$ was added to the anthracenecontaining SDS solution (without gold), the absorption peak at $253 \mathrm{~nm}$ remains unchanged. These results suggest that the gold NP plays an important role in the catalytic reaction. To further understand whether gold NPs participate in the catalytic reaction, we first prepared gold NPs in an aqueous SDS solution and then mixed them with the anthracene-containing SDS solution (Scheme 1). When $\mathrm{NaBH}_{4}$ was finally added to the above-described solution, the decrease in absorbance was observed again. It is concluded that no matter whether gold NPs were produced in situ or pre-prepared, they all show catalytic activity. For comparison, when the Au NP and anthracene-containing SDS solution were stirred under an atmosphere of $\mathrm{H}_{2}$, the decrease in the absorption peak at $253 \mathrm{~nm}$ was slower than that with $\mathrm{NaBH}_{4}$. For the reduction with $\mathrm{NaBH}_{4}$, the decrease of the $253 \mathrm{~nm}$ peak was usually observed within a few minutes, but the absoprtion change observed for the hydrogen reduction lasted a few days. Thus, we will concentrate on the use of $\mathrm{NaBH}_{4}$ as reductant herein. We note, however, the difference in the reaction rate suggested that the indirect influence of $\mathrm{H}_{2}$ produced from $\mathrm{NaBH}_{4}$ on the hydrogenation was insignificant.

On the other hand, the difference on the catalytic activity between the CTAB and the SDS system is prominent. When $\mathrm{HAuCl}_{4}$ and $\mathrm{NaBH}_{4}$ were successively added to the anthracenecontaining $C T A B$ solution, the UV/Vis absorption spectrum in Figure $2 \mathrm{~b}$ shows that gold NPs are formed as expected, but $\mathrm{a}$ small decrease in the $253 \mathrm{~nm}$ absorption peak of anthracene is observed as well. At the same time, we first prepared gold NPs in an aqueous CTAB solution and then mixed them with the anthracene-containing CTAB solution. When $\mathrm{NaBH}_{4}$ was finally introduced to the above-described solution, no decrease in the anthracene absorbance was observed. To study the size effect of gold NPs in the catalyic reaction, we need to vary the particle size of the gold NP. Gentle heating can serve for this purpose. The Au@CTAB system was heated $\left(\right.$ at $80^{\circ} \mathrm{C}$ ) to let the $A u$ NPs grow bigger. Figure $2 \mathrm{c}$ shows how the SPR band of gold NPs gradually becomes sharper at increasing heating time, indicating the formation of bigger Au NPs (confirmed by TEM). Then, after the grown Au@CTAB NPs were mixed with anthracene followed by the addition of $\mathrm{NaBH}_{4}$, the substantial decrease in the $253 \mathrm{~nm}$ absorption peak of anthracene was observed again (inset of Figure $2 \mathrm{c}$ ). The larger-sized Au@CTAB NP showed stronger catalytic activity than the original Au@CTAB NP although the larger-sized NP has a smaller surface area. Comparing Au@SDS and Au@CTAB, we also observe the same trend. Thus, the catalytic activity of $A u$ is mainly determined 
a)

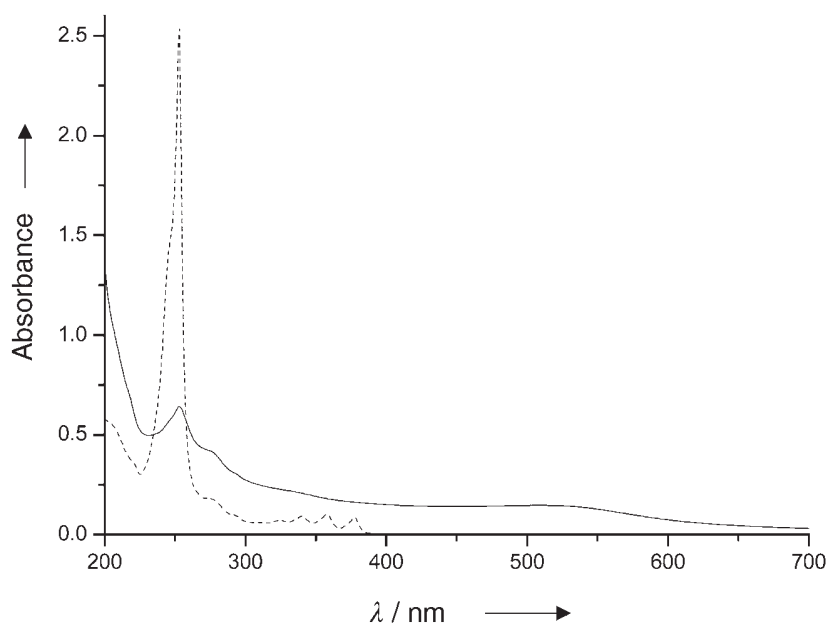

b)

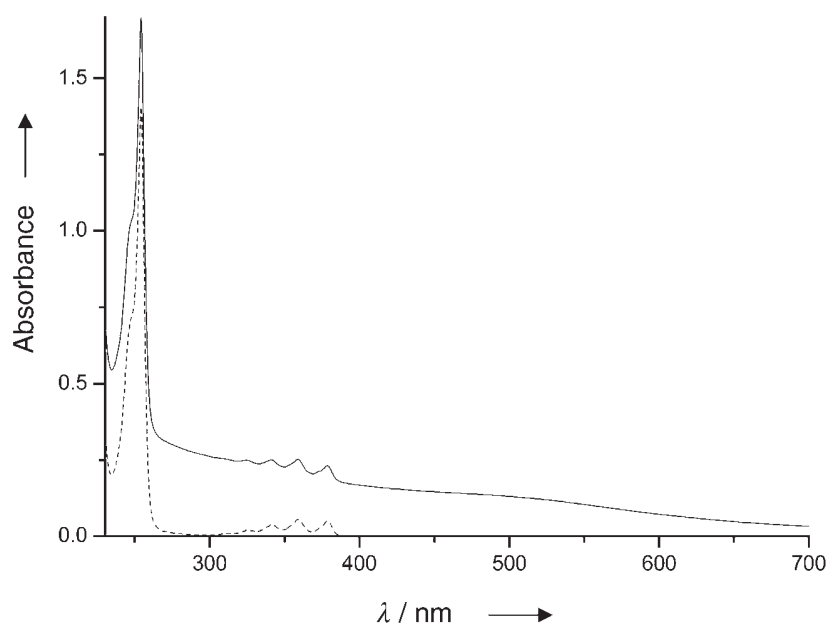

c)

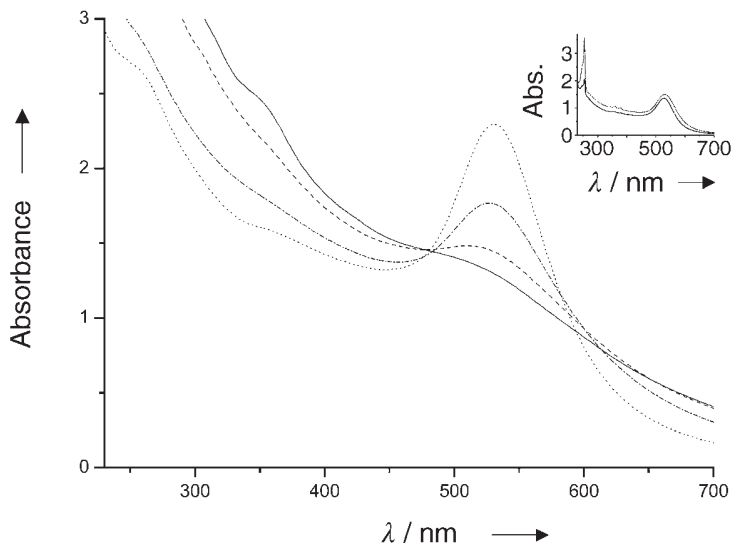

Figure 2. a) UV/Vis spectra of anthracene in $5 \mathrm{~mL}$ aqueous solution of SDS (20 mM) before $(---)$ and after (-) adding $10 \mu \mathrm{L} \mathrm{HAuCl}_{4}$ and $30 \mu \mathrm{L} \mathrm{NaBH}_{4}$. Conditions: [anthracene $]=15.3 \mu \mathrm{M}$, $\left[\mathrm{HAuCl}_{4}\right]=25 \mathrm{~mm}$ and $\left[\mathrm{NaBH}_{4}\right]=26.5 \mathrm{mM}$. b) UV/Vis spectra of anthracene in $5 \mathrm{~mL}$ aqueous solution of CTAB $(0.1 \mathrm{M})$ before (----) and after (-) adding $10 \mu \mathrm{L} \mathrm{HAuCl}_{4}$ and $30 \mu \mathrm{L} \mathrm{NaBH}_{4}$. Conditions: [anthracene] $=8.4 \mu \mathrm{M}$, $\left[\mathrm{HAuCl}_{4}\right]=25 \mathrm{~mm}$ and $\left[\mathrm{NaBH}_{4}\right]=11 \mathrm{~mm}$. c) Successive UV/Vis spectra of gold particles prepared in $300 \mathrm{~mL}$ aqueous solution of CTAB $(5 \mathrm{~mm})$ before (-) and after $(\cdots .$.$) heating at 80^{\circ} \mathrm{C}$ for $24 \mathrm{~h}$, and during the period of heating (---- and -•-•). Conditions: $\left[\mathrm{HAuCl}_{4}\right]=25 \mathrm{~mm}, 9 \mathrm{~mL}$ and $\left[\mathrm{NaBH}_{4}\right]=11 \mathrm{~mm}, 27 \mathrm{~mL}$. The inset shows the UV/Vis spectra of the solution of the above-described gold particles with anthracene before (----) and after (-) the reduction by using $\mathrm{NaBH}_{4}$. by its size, and not by the charge of the surfactant. There seems to be an optimum size for the catalytic effect.

A reaction catalyzed by gold NPs in a CTAB- $\mathrm{D}_{2} \mathrm{O}$ solution was analyzed by NMR spectroscopy. The ${ }^{1} \mathrm{H}$ NMR spectrum showed that the product has two peaks at 7.4 and $7.3 \mathrm{ppm}$ which are assigned to aromatic protons. And another singlet peak is observed at $4.0 \mathrm{ppm}$. The integral ratio between those three peaks is $1: 1: 1$. Therefore, it was concluded that the product obtained in the reaction of anthracene catalyzed by gold NPs is 9,10-dihydroanthracene. In addition to anthracene, other anthracene derivatives such as 9-phenylanthracene and 1,2-benzanthracnene can also undergo the hydrogenation reaction catalyzed by gold NPs.

If the added amount of $\mathrm{NaBH}_{4}$ was not high enough to completely reduce $\mathrm{HAuCl}_{4}$ in the solution at once, side products can be observed in the final reaction solution beside 9,10-dihydroanthracene. The side products are the result of the oxidation of anthracene by the oxidizing reagent-a $\mathrm{Au}^{\text {III }}$ complex. Oxidation of anthracene will take place if both $\mathrm{Au} \mathrm{NP}$ and $\mathrm{Au}$ complex exist in the anthracene solution. In the normal case, $\mathrm{HAuCl}_{4}$ was completely reduced in the solution to form $\mathrm{Au}$ NPs. Then, only the hydrogenation of anthracene occurred at the surface of the Au NPs. If some $\mathrm{Au}^{\mathrm{III}}$ species were leached from the Au NPs, it is expected that some oxidation products, in addition to 9,10-dihydroanthracene, would be observed at the same time. But only 9,10-dihydroanthracene was obtained in our case. Therefore, leaching of $\mathrm{Au}^{\text {III }}$ from Au NPs may be excluded and the Au NP is the true catalytic agent.

We then studied the size effect of the Au NP on the catalytic reduction of anthracene. We use four different sizes of the Au NP. The size of the surfactant-protected gold NPs can be controlled by the properties of the surfactant used and the amount of the catalyst, we thus prepared four colloidal Au NP systems with different mean diameters. The smallest system $(2.7 \mathrm{~nm})$ was prepared in a $0.1 \mathrm{M}$ CATB solution and the others $(5.4,10.8$ and $24.7 \mathrm{~nm}$ ) in a $20 \mathrm{~mm}$ SDS solution. To compare their different activities in the catalytic hydrogenation of anthracene, the same numbers of moles of $\mathrm{NaBH}_{4}$ were added to each of the four solutions. After measuring the absorption spectra, we then calculated the relative ratios $(R)$ of the absorption decrease at $253 \mathrm{~nm}$ for the four Au NP solutions relative to the case of a particle size of $24.7 \mathrm{~nm}$. $R$ as defined in Equation (1) is normalized by the concentration of $\mathrm{Au}$ in the solution of the gold NP.

$R=\frac{\Delta A_{\mathrm{N}} V_{\mathrm{N}} / n_{\mathrm{Au}, \mathrm{N}}}{\Delta A_{24.7} V_{24.7} / n_{\mathrm{Au}, 24.7}}$ 
In Equation (1), $\Delta A$ is the absorption decrease at $253 \mathrm{~nm}, N$ is the particle size, and $V_{\mathrm{N}}$ is the solution's volume. $n_{\mathrm{Au}}$ gives the molar amount of $\mathrm{Au}$ in the solution of gold NPs. The concentration $\left(n_{\mathrm{Au}} / V_{\mathrm{N}}\right.$ in $\left.\mathrm{mM}\right)$ at four different sizes are $0.2(24.7 \mathrm{~nm})$, $0.07(10.8 \mathrm{~nm}), 0.017(5.4 \mathrm{~nm})$ and $0.75(2.7 \mathrm{~nm})$. Figure $3 \mathrm{a}$ illustrates a marked size effect of the catalytic activity of gold particles for the hydrogenation of anthracene, and gold particles with a mean diameter of $5.4 \mathrm{~nm}$ exhibit the maximum activity. Figure $3 \mathrm{~b}$ shows the conversion of anthracene catalyzed by a $\mathrm{Au} N \mathrm{NP}$ with a size of $5.4 \mathrm{~nm}$ (in Figure $3 \mathrm{a}$ ) after successive addition of $\mathrm{NaBH}_{4}$ with increasing time. Because the characteristic absorption peak of anthracene at $359 \mathrm{~nm}$ is absent in 9,10-dihydroanthracene, anthracene conversion could easily be followed by measuring the absorbance at $359 \mathrm{~nm}$. For each measurement, about $15 \%$ of anthracene conversion was observed

a)

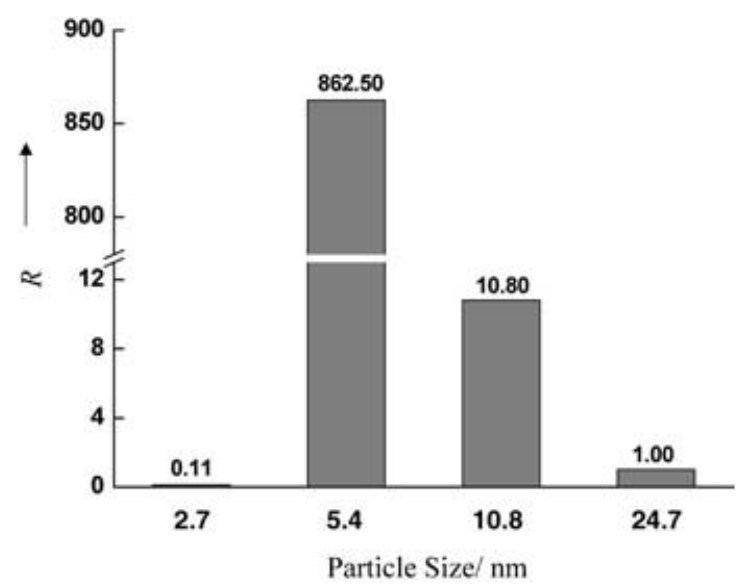

b)

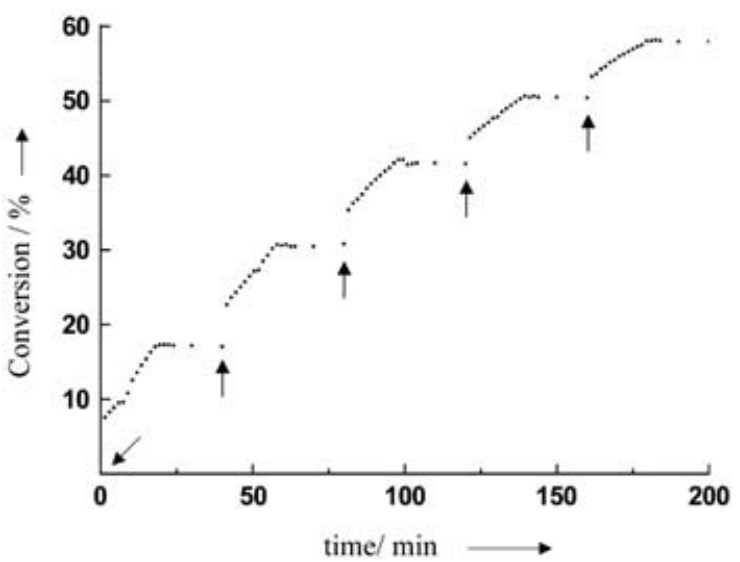

Figure 3. a) Relative ratios $(R)$ of the absorption decrease at $253 \mathrm{~nm}$ for four solutions containing gold particles of different sizes (relative to the case of a particle size of $24.7 \mathrm{~nm}$ ). The same molar fractions of $\mathrm{NaBH}_{4}$ were separately added to each of the four solutions. The molar concentrations (in $\mathrm{mm}$ ) of $\mathrm{Au}$ in the solutions with four different particle sizes are $0.2(24.7 \mathrm{~nm}), 0.07$ $(10.8 \mathrm{~nm}), 0.017(5.4 \mathrm{~nm})$ and $0.75(2.7 \mathrm{~nm})$. b) The activity of the gold particle with a size of $5.4 \mathrm{~nm}$ (a) in anthracene hydrogenation is shown. $[\mathrm{Au}]=5 \mu \mathrm{M}$ and [anthracene] $=138.5 \mu \mathrm{M}$. The arrows indicate the time of adding equal amounts of $\mathrm{NaBH}_{4}$. after adding the same amount of reducing reagent. This shows that the Au NPs preserve their constant catalytic activity after repeated catalytic actions.

First we discuss the difference of sizes of Au NPs prepared by using cationic and anionic surfactants. We sketch a scenario accounting for the formation of gold NPs in the ionic surfactant systems. The $\mathrm{AuCl}_{4}^{-}$anions, which are expelled from the SDS micelles due to electrostatic repulsions, are free ions in the SDS solution. An embryonic gold NP rapidly forms when reduction occurs. Subsequently, capping by the SDS surfactant molecules quenches the growth of gold NPs. If gold NPs are formed too fast for the nearby surfactants to be trap during the period of nucleation, then the particle will grow to a larger size in the Au@SDS system. In contrast, the $\mathrm{AuCl}_{4}{ }^{-}$anions are attracted by the oppositely charged CTAB micelles and are adsorbed on the cationic micelles. When reduction occurs, the embryonic gold NP could be immediately trapped by the micelles in which the $\mathrm{AuCl}_{4}^{-}$anions were absorbed. Therefore, the size of the gold NP produced in the CTAB solution was smaller than that in the SDS solution.

Because anthracene and gold NPs are surrounded by the surfactant molecules in our reaction systems, anthracene molecules should be located near the surface of gold NPs. When $\mathrm{NaBH}_{4}$ was added to the solution, the hydride formed from $\mathrm{NaBH}_{4}$ could be trapped by surfactants at the surface of gold NPs. Then, the hydride could be adsorbed on the surface of gold NPs and subsequently activated to attack an anthracene molecule nearby. Recently, gold hydride anions have been observed in the solid matrix of laser-ablated gold with $\mathrm{H}_{2}$ at low temperature. ${ }^{[14 a]}$ Theoretical calculations also suggested that the gold cluster hydride anion is of lower energy than its corresponding neutral one (for example, AuAuH ${ }^{-}$and AuAuH). ${ }^{[14 b]}$ Maybe there is an electron transfer through the Au NP to the anthracene molecule and subsequently hydrogen at the surface of gold NPs reacted with the activated anthracene. For a large enough Au NP, the overall reaction rate of the hydrogenation would be monotonously increasing with decreasing size of gold NPs. However, the dramatic decrease of catalytic activity for the very small-sized Au@CTAB is rather intriguing. There seems to be an optimum size, between 3 to $5 \mathrm{~nm}$, for the catalytic hydrogenation of anthracene. This behavior is not unlike the size-dependent behavior observed for the well-studied CO oxidation catalyzed by gold NPs. ${ }^{[3]}$ Also Jia et al. found that the selective gas-phase hydrogenation of acetylene over a $\mathrm{Au} /$ $\mathrm{Al}_{2} \mathrm{O}_{3}$ catalyst showed a maximum activity at a Au NP diameter of about $3.0 \mathrm{~nm}^{[4]}$ Goodman an co-workers attributed the reduced activity of small-sized Au NP to the appearance of nonmetallic properties. ${ }^{[15]}$ This conjecture has been difficult to study for real gas-phase catalytic reactions when Au NPs are deposited on the surface of a support. The catalytic activity depends not only on the particle size of $\mathrm{Au}$, but also on the nature of the support and the preparation method of the catalyst. ${ }^{[16]}$ Moreover, these factors are often inter-related such that a single contribution cannot be disentangled. Strong metalsupport interactions may also be size-dependent. Thus it is difficult to attribute a "pure" quantum electronic size effect to the catalytic action. 
In our system, the capping surfactant molecules presumably do not electronically interact with gold, and the Au NP functions as an electron transfer agent during the reduction. One may thus witness a "pure" electronic size effect in the catalytic reduction reaction. We may thus postulate that the semi-conducting property of the very small-sized Au NP hinder the electron relay. This may be the main reason for the reduced activity of Au NPs with a size of less than $3 \mathrm{~nm}$ observed in our experiments.

In conclusion, we have successfully synthesized ionic surfactant-protected gold NPs whose particle sizes may be controlled by the properties and quantity of surfactants used for the preparation. It was shown that gold NPs in aqueous micellar solutions catalyze the hydrogenation of anthracene at room temperature. For the first time, a unique size effect for the catalysis in gold colloid solutions is found. Because of the elimination of solid supports, the confined space surrounded by surfactants paves the way for a precise study of the solutionphase catalysis of well-controlled metal NPs.

\section{Acknowledgments}

This work was supported by a grant from the Ministry of Education of Taiwan through the Area of Excellent program.

Keywords: colloids • electrochemistry - heterogeneous catalysis $\cdot$ nanoparticles $\cdot$ structure-activity relationships

[1] a) A. Roucoux, J. Schulz, H. Patin, Chem. Rev. 2003, 102, 3757; b) L. N. Lewis, Chem. Rev. 1993, 93, 2693; c) G. Schmid, Chem. Rev. 1992, 92, 1709.

[2] a) G. C. Bond, D. T. Thompson, Catal. Rev. Sci. Eng. 1999, 41, 319; b) A. M. Argo, J. F. Odzak, B. C. Gates, J. Am. Chem. Soc. 2003, 125, 7107.

[3] a) M. Haruta, Chem. Rec. 2003, 3, 75; b) T. Hayashi, K. Tanaka, M. Haruta, J. Catal. 1998, 178, 566.

[4] J. Jia, K. Haraki, J. N. Kondo, K. Domen, K. Tamaru, J. Phys. Chem. B 2000, 104,11153

[5] M. Okumura, T. Akita, M. Haruta, Catal. Today 2002, 74, 265.

[6] T. V. Choudhary, C. Sivadinarayana, A. K. Datye, D. Kumar, D. W. Goodman, Catal. Lett. 2003, 86, 1.

[7] a) P. Mukherjee, C. R. Patra, A. Ghosh, R. Kumar, M. Sastry, Chem. Mater 2002, 14, 1678; b) S. Naito, M. Tanimoto, J. Chem. Soc. Chem. Commun. 1988, 832; c) G. C. Bond, P. A. Sermon, G. Webb, D. A. Buchanan, P. B. Wells, J. Chem. Soc. Chem. Commun. 1973, 444.

[8] C. Mohr, H. Hofmeister, M. Lucas, P. Claus, Chem. Eng. Technol. 2000, 23, 324.

[9] J. E. Bailie, H. A. Abdullah, J. A. Anderson, C. H. Rochester, N. V. Richardson, N. Hodge, J. G. Zhang, A. Burrows, C. J. Kiely, G. J. Hutchings, Phys. Chem. Chem. Phys. 2001, 3, 4113.

[10] C. Milone, R. Ingoglia, A. Pistone, G. Neri, F. Frusteri, S. Galvagno, J. Catal. 2004, 222, 348.

[11] a) M. Comotti, C. D. Pina, R. Matarrese, M. Rossi, Angew. Chem. 2004 116, 5936; Angew. Chem. Int. Ed. 2004, 43, 5812; b) L. Pasquato, F. Rancan, P. Scrimin, F. Mancin, C. Frigeri, Chem. Commun. 2000, 2253 c) R. M. Crooks, M. Zhao, L. Sun, V. Chechik, L. K. Yeung, Acc. Chem. Res. 2001, 34, 181; d) H. Bönnemann, W. Brijoux, A. S. Tilling, K. Siepen, Top. Catal. 1997, 4, 217.

[12] a) Z. H. Zhang, K. Okada, M. Yamamoto, T. Yoshida, Catal. Today 1998 45, 361; b) M. Yalpani, Chem. Ber. 1990, 123, 983.

[13] V. Subramanian, E. E. Wolf, P. V. Kamat, J. Am. Chem. Soc. 2004, 126, 4943.
[14] a) X. Wang, L. Andrews, Angew. Chem. 2003, 115, 5359; Angew. Chem. Int. Ed. 2003, 42, 5201; b) X. Wang, L. Andrews, L. Manceron, C. Marsden, J. Phys. Chem. A 2003, 107, 8492.

[15] M. Valden, X. Lai, D. W. Goodman, Science 1998, 281, 1647.

[16] M. M. Schubert, S. Hackenberg, A. C. van Veen, M. Muhler, V. Plzak, R. J. Behm, J. Catal. 2001, 197, 113.

Received: March 31, 2005

Revised: July 15, 2005 